\title{
Municipal infrastructure management and its impact on service delivery in the City of Ekurhuleni
}

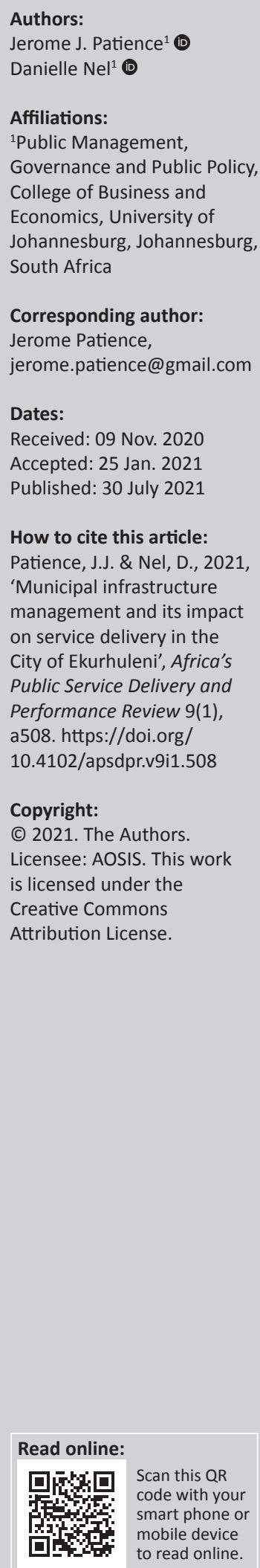

Background: Property, plant and equipment (PPE) represent a significant portion of the asset base of any municipality and thus a municipality has a moral and legislative duty to safeguard these assets against damage and/or wilful neglect.

Aim: This article explored how infrastructure management within the City of Ekurhuleni (COE), Gauteng province in the Republic of South Africa, can assist in the provision of sustainable services and how the city's infrastructure can contribute to social and economic development of its communities. This article endeavours to indicate how the COE manages its infrastructure in terms of three service delivery departments as a sample of the entire municipality. This article focuses on the improvement of infrastructure management in general and at the $\mathrm{COE}$, in particular. It further aims to indicate how service departments can go about in employing asset-management guidelines whilst improving governance strategies.

Methods: This study followed a mixed-method approach and the system's theory served as the research methodology. The study covered a 5-year period from 2014/2015 to 2018/2019 financial years and employed benchmarking ratios and calculations to indicate how best the city can improve its management of infrastructure, and measure its performance against those of equally sized metropolitan municipalities.

Results: The findings of the study reveal that even though the city is doing well in terms of certain aspects of service delivery, there still remain many issues regarding the management of infrastructure that impede its ability to provide sustainable services that can ultimately lead to economic growth and development.

Conclusion: Recommendations to the city include the upskilling of especially the senior management in terms of the critical role they play in maintaining the city's infrastructure assets. Another recommendation is that politicians do not only think in terms of adding to the city's current infrastructure whilst not attending to the maintenance of existing assets and most critically, the city does not follow an integrated approach in terms of the comprehensive infrastructure programme.

Keywords: basic services; infrastructure management; service delivery; service backlogs; basic services; protests; sustainable services; socio-economic development.

\section{Introduction}

Municipalities are the nearest to communities in terms of the provision of sustainable basic services. For the greater part of our democracy, government has reduced citizens to passive beneficiaries of its assistance, whilst many are still waiting for these services to arrive (Schermbrucker 2020:1). Communities are breaking down municipal infrastructure in an attempt to get the attention of their councillors to attend to their grievances in terms of service delivery challenges. Many of these grievances are a result of the ill management and/or non-maintenance of infrastructure, and the consequence thereof is that access to basic services remains elusive for many communities (Sosibo 2014). Many municipalities in South Africa (SA) find it difficult and sometimes impossible to follow the constitutional mandate of delivering sustainable basic services because of their inability to manage their assets effectively and thereby, mitigating risks. Schermbrucker (2020:1) states that for development and growth of communities to take place, we first have to fix our municipalities.

Ekurhuleni is pronounced as e-koo-roo-le-ni, and the city is one of three metropolitan cities in the province of Gauteng in the SA. Ekurhuleni is a Tsonga (one of 11 official languages of SA) word that means place of peace. This Tsonga word symbolises the diversity of the city's people and its vision of an equitable and progressive community (City of Ekurhuleni [COE] 2015). 
Gauteng province consists of three metropolitan cities namely the City of Johannesburg (COJ), City of Tshwane (COT) and the COE, and two district municipalities, namely West Rand and Sedibeng. The COE abuts the COJ to the west, COT to the north, Sedibeng District Municipality to the south and the province of Mpumalanga to the east. The COE is a category A municipality and covers a land area of $1975 \mathrm{~km}^{2}$. In terms of Section 155 (1) (a) of the Constitution of the Republic of SA, Act no. 108 of 1996 (hereafter referred to as the Constitution [Republic of South Africa, 1996]), a category A municipality has an exclusive municipal executive and legislative authority in its demarcated area. According to the South African national census of 2011 (updated figures not available yet), the COE had a population of 3178470 people. This means that the $\mathrm{COE}$ is the fourth most populated metropolitan city in SA after the COJ (4 434 827), COT (3 740 026) and the City of eThekwini (3 442 361) in Durban (Statistics South Africa [StatsSA] 2012:n.p.).

The COE's property, plant and equipment (PPE) total for the 2019-2020 financial year was R60 billion (COE 2020b:A6), a figure that is greater than most African countries' gross domestic product (GDP). The PPE total of R60b equates to the United States $\$ 3.905 \mathrm{~b}$ at the current rate of exchange of US\$1 equals R15.36 as on 08 January 2021 (Currency Converter 2021:n.p.). This type of investment requires the city to guard its asset base against damages and wilful neglect. In the last few years, there has been an upsurge in the number of protests by communities demanding improved municipal services by communities, which reflect the importance of this issue.

At present, most municipalities fail to obtain a clean or unqualified audit opinion from the Auditor General (AG) because of their inability to account for their assets, and their internal control over these assets does not comply with the Generally Recognised Accounting Practice (GRAP) 17. A clean audit indicates that the financial statements are free from material misstatement and there are no material findings on performance reporting, whilst an unqualified audit opinion means that findings have been raised on either financial or performance reporting in terms of stated objectives, unless the AG expressed a clean audit outcome (Auditor General 2012:4-5).

The Municipal Systems Act (MSyA) states that a municipality has a duty to ensure that services are provided to the local community in a financially and environmentally sustainable manner (Section 4[2]d of the MSyA). Good Asset Management (AM) facilitates the provision of basic services in a financially sustainable manner.

In its endeavour to achieve the constitutional objectives of the local government in terms of Section 152, this article aims to see how optimally the COE manages its infrastructure assets. The objectives of local government are:

- To provide democratic and accountable government for local communities.
- To ensure the provision of services to communities in a sustainable manner.

- To promote social and economic development.

- To promote a safe and healthy environment.

- To encourage the involvement of communities and community organisations in the matters of local government (Section 152 of the Constitution).

To meet these objectives, the COE has to employ its infrastructure to the best of its ability, because the rendering of services requires good infrastructure management and the maintenance thereof. For cities to be dynamic and entrepreneurial, infrastructure assets are to be properly managed so that social and economic development are promoted and communities can be proud of their cities as all these contribute to economic growth, development and general prosperity.

\section{Methodological approach}

This descriptive study followed a mixed-method approach with a predominantly qualitative research design. This study also has a quantitative element in order to determine the relationship between the independent $q$ variables and the dependent variables in the population and it thus establishes associations between the variables. Babbie (2010:12) is of the view that a quantitative analysis is a numerical representation and manipulation of observations aimed at describing and explaining the phenomena reflected by those observations. As the qualitative data has priority, it was collected first followed by quantitative data. The researcher triangulated the quantitative data in order to integrate the data to obtain a logical, practical and holistic approach to the research questions and objectives. The phenomenon of infrastructure management requires more than just a single source of information and the utilisation of the reviewed literature established the study's theoretical framework and foundations. In terms of data-collection methods, the researcher studied and analysed relevant literature, interviews, observations, questionnaires, annual reports, audited annual financial statements and council approved budgets.

\section{Conceptual and theoretical analysis}

Concepts central to the study include good governance, municipal infrastructure management, risk management, backlogs, basic municipal services, service delivery, community protests, etcetera. According to Neuman (1997:39), concepts are building blocks of theory expressed as symbols or words. A conceptual framework is defined as a network or a 'plane' of linked concepts and the conceptual framework analysis offers the procedure of theorisation for building the different conceptual frameworks that are based on grounded theory (Jabareen 2009:49).

The study used the systems theory as its theoretical framework because municipalities as public institutions function within a larger picture of the total environment. This interrelationship between various subsystems requires holistic thinking and an understanding of the consequences of actions one system has 
on another. Gildenhuys and Knipe (2000:114) state that the aim of the systems theory is external efficiency and effectiveness that means that it strives to satisfy the needs of the public optimally, instead of only focussing on internal efficiency and effectiveness of the administration. According to Van der Waldt and Auriacombe (2015):

A system can be seen and described as a set of interdependent components that form a whole, and a municipality can be viewed as a system consisting of four basic elements namely:

- Inputs (resources and equipment - Supply chain)

- Processing (utilising structures, systems, procedures, policies etc. to convert inputs into outputs);

- Outputs (services and/or products);

- Feedback (responses of clients regarding the quality and quantity of services and/or products they received from public institutions). (p. 12)

The researcher employed the classification model or framework in the analysis of the collected data from the three municipal departments. Using the various elements of the systems theory, the researcher was able to code and plot the data. These elements also formed the basis of interpretation of the findings and results in order to propose recommendations to the city.

The questionnaire was developed with the assistance of municipal colleagues who indicated where there were perhaps repetitions, how best to structure a sentence in order to prevent ambiguities, and to get answers by asking probing questions. Questionnaires were sent to certain identified officials in the departments of Energy, Water \& Wastewater and Roads \& Stormwater for them to peruse in the meantime. Officials were requested to keep their answers for the focus group meetings (interviews) and it was during these interviews that greater clarity was obtained from departments.

Open-ended interviews formed the primary data and the major focus was on qualitative data whilst quantitative data were used to determine deviations or variances if any. In instances where there were variances, these were used to compare it against prescribed regulations and guidelines from the National Treasury (NT) and other national and provincial sector departments. Secondary data comprised reports, statistics, newspaper articles, journals and other magazine articles.

The population in this study comprises local government in general which means that municipalities will benefit greatly from the outcomes of this study. This research study employed the judgemental or purposive sampling approach because the researcher selected the most productive sample to answer the research questions. Purposive sampling is an acceptable kind of sampling for special situations, in that it uses the judgment of an expert in selecting cases or it selects cases with a specific purpose in mind (Neuman 1997:206). Marshall (1996:523) further indicates that the purposive sample approach can involve a framework of the variables that might influence an individual's contribution and will be based on the researcher's practical knowledge of the research area, the available literature and evidence from the study itself. The advantage of using the purposive sample approach is that it is a better intellectual strategy where subjects had to have specific experiences and expertise in their field of specialisation such as energy, water, wastewater, roads and storm water. The snowball sampling approach was also used and subjects recommended other candidates who were more useful than they were in answering the research questions, especially in the department of Roads \& Stormwater.

The COE served as the unit of analysis, and the advantage of this was that the interviewees were all qualified officials in their field of specialisation with many of them having more than 20 years of experience. The sample comprised three departments of COE, namely departments of Energy, Water \& Wastewater and Roads \& Stormwater. Three respondents each from the Energy and Water \& Wastewater departments and one respondent from the Roads \& Stormwater department were interviewed, therefore, constituting seven respondents. The departments interviewed represent the municipality aptly in terms of infrastructure management because the high-value infrastructure is mainly based in these departments. The sample is also indicative of the type of service delivery actions that are mostly under scrutiny by the public and the media. These departments are crucial for the city to meet its constitutional objectives of sustainable service delivery and supporting local economic development.

During the selective coding phase, four categories were extrapolated and these were triangulated from the conceptual and the theoretical underpinnings (see Figure 1). It was also during the axial coding phase that quantitative results were triangulated with the information obtained during interviews.

The 10 categories were a result of triangulation of the qualitative analysis and documentary analysis of the quantitative information that supported the qualitative findings. This classification model or framework served as the tool to contextualise the units of analysis of the different themes or core categories.

\section{Institutional and regulatory environment}

The government issued a number of laws, guidelines, regulations and circulars regarding service delivery and infrastructure management in order to address service delivery mechanisms at the municipal level. The constitution provides the basis for all laws in the republic. Chapters and sections that relate to service delivery and infrastructure management in the constitution include Chapter 3 (co-operative governance), Chapter 7 (local government), Chapter 10 (public administration). Other sections and parts include Section 139 (provincial intervention in local government), Section 216 (treasury control) and Parts B of both Schedules 4 and 5 (dealing with local government matters as set out in Sections 155[6][a] and [7]). Local Government: Municipal Structures Act, Act no. 117 of 1998 (hereafter referred to as the Structures Act [Republic of South Africa 1998]). The chapters and sections that relate to municipal service delivery and infrastructure management include Chapter 1 (categories and types of municipalities), 


\begin{tabular}{|c|c|c|c|c|c|}
\hline \multicolumn{6}{|c|}{ Questionnaire } \\
\hline No. & Selective coding categories & $\begin{array}{l}\text { Input from the } \\
\text { environment }\end{array}$ & $\begin{array}{l}\text { Processing of } \\
\text { inputs }\end{array}$ & $\begin{array}{l}\text { Outputs to the } \\
\text { environment }\end{array}$ & Feedback \\
\hline 1 & Condition of infrastructure and infrastructure management challenges & $\mathbf{x}$ & $\mathbf{x}$ & $\mathbf{x}$ & $\mathbf{x}$ \\
\hline 2 & Risks in EMM's infrastructure management & $\mathbf{x}$ & $\mathbf{x}$ & $\mathbf{x}$ & $\mathbf{x}$ \\
\hline 3 & Relationship between improved infrastructure management \& good governance & $\mathbf{x}$ & $\mathbf{x}$ & $\mathbf{x}$ & $\mathbf{x}$ \\
\hline 4 & Solutions to improve the identified gaps & $\mathbf{x}$ & $\mathbf{x}$ & $\mathbf{x}$ & $\mathbf{x}$ \\
\hline No. & Categories identified from the research analysis (axial coding) & $\begin{array}{l}\text { Input from the } \\
\text { environment }\end{array}$ & $\begin{array}{l}\text { Processing of } \\
\text { inputs }\end{array}$ & $\begin{array}{l}\text { Outputs to the } \\
\text { environment }\end{array}$ & Feedback \\
\hline 1 & R \& M budget & $\mathbf{x}$ & & & \\
\hline 2 & Control & & $\mathbf{x}$ & & \\
\hline 3 & Operational/continued repairs & & $\mathbf{x}$ & & $x$ \\
\hline 4 & Improved services & & & $\mathbf{x}$ & $\mathbf{x}$ \\
\hline 5 & Human capacity & $\mathbf{x}$ & & & \\
\hline 7 & Infrastructure management & $\mathbf{x}$ & & & \\
\hline 8 & Population growth & & & & $\mathbf{x}$ \\
\hline 9 & $R$ \& $M$ expenditure reporting & & $\mathbf{x}$ & & $\mathbf{x}$ \\
\hline 10 & Government frameworks, regulations, legislation, policies, stakeholders, resources & $\mathbf{x}$ & & & \\
\hline
\end{tabular}

EMM, Ekurhuleni Metropolitan Municipality; R\&M, repairs and maintenance.

FIGURE 1: Schematic presentation of triangulated responses (selective and axial coding) to the interview questionnaire.

Chapter 2 (establishment of municipalities), Section 64 (functions and powers of metropolitan councils) and Part 4 of Chapter 4 that deals with ward committees. Local Government: MSyA, Act no. 32 of 2000 (hereafter referred to as the Systems Act [Republic of South Africa 2000]). The chapters and sections that relate to municipal service delivery and infrastructure management include Chapter 3 (municipal functions and powers), Chapter 4 (community participation), Chapter 5 (integrated development planning), Chapter 6 (performance management), Chapter 7 (local public administration and human resources) and Chapter 8 (municipal services). Local Government: Municipal Finance Management Act, Act no. 56 of 2003 (hereafter referred to as the MFMA [Republic of South Africa 2003]). The chapters and sections of the MFMA that relate to municipal service delivery and infrastructure management include Chapter 1 (objects of the act), Chapter 2 (supervision over local government finance management), Chapter 4 (municipal budgets), Chapter 5 (co-operative government). Other chaptersincludeChapter7(responsibilities of mayors), Chapter 8 (responsibilities of municipal officials), Chapter 12 (financial reporting and auditing) and Chapter 14 (general treasury matters). Section 4(e) of the Draft Municipal Performance Management Regulations of 2001 sets out the capital investment framework that municipalities are to use in their development programmes whilst Section 21 of the Spatial Planning and Land Use Management Act, Act no 16 of 2013 determine what the contents of a municipality's spatial development framework should be.

\section{The role of infrastructure management in sustainable service provision}

The local government has to ensure the rendering of services to communities in a financially and environmentally sustainable manner (Section 4[2]d of the Systems Act). Through the employment of good AM principles and systems, municipalities can achieve a sustainable financial provision of basic services. From the ever-increasing number of service delivery protests it is evident that many municipalities find it difficult or nearly impossible to perform their constitutional mandate to the disadvantage of communities and the entire country.

The rendering of basic municipal services ensures social health and well-being that ultimately support economic growth (Boshoff 2009:1). Municipal infrastructure and public infrastructure in general is deteriorating very fast because many assets are overloaded, or they are no long operational or in desperate need of complete overhaul.

Service delivery does not only indicate a lack of services but generally includes failing communities because municipalities do not maintain their existing infrastructure which is the main cause of the current state of municipal infrastructure (Boshoff 2009:1). The Department of Cooperative Governance and Traditional Affairs (CoGTA 2009:90) identified a number of deficiencies within municipalities and some of these include:

- Municipalities are struggling with their governance and financial management that ultimately affect service delivery negatively.

- Poor infrastructure (capital) planning with no deliberate, targeted and programmatic approach by councils that can help communities to have universal access to services, thus eradicating serious service delivery backlogs.

- Many municipalities fail to develop a differentiated rationale for managing their infrastructure investment and thus have insufficient leveraging of alternative approaches to service provision.

- The national government also exacerbates the problem in that there is no clear funding and delivery strategy for the provision and operationalisation of infrastructure that can support the especially weaker municipalities (CoGTA 2009:90).

The local government has to give serious attention to these challenges by acting swiftly and ridding itself from the 
already negative perception people have of this important level of governance.

\section{Challenges affecting municipal infrastructure provision}

In terms of Section 157 of the Constitution, the municipal council is vested with executive and legislative authorities and as such, exercises discretion with the formulation and adoption of policies and bylaws in the areas listed in Part B of Schedule 4 and Part B of Schedule 5 of the Constitution. The Overview Report on the state of Local Government in SA issued by CoGTA (2009:9) states that municipalities' dysfunctionality and instability are creating opportunities for fraud and corruption. In order to stem these challenges, CoGTA established the Local Government Turn-Around Strategy.

In the global economy, the state of a nation's physical infrastructure provides one of the best indicators of its likely prosperity (South African Institute of Civil Engineers [SAICE] 2011:10). A prosperous economy leads to the efficient functioning of systems, for example, transport, energy, water, sanitation and waste management and these produce social infrastructural services that draw investments to such a city or country.

\section{Asset management}

Every year AM is a matter of emphasis by the AG for most municipalities, and the reason why these municipalities receive qualified audit reports, and even disclaimers (AG 2011-2012 report). Asset management is a broad function that includes a structured process of decision making, planning and control over the acquisition, use, safeguarding and disposal of assets to maximise their service delivery potential and benefits, and to minimise their related risks and costs over their entire life (NT 2008:3).

Lack of adequate asset registers, unavailability of supporting documentation to substantiate asset values and the valuation of assets in accordance with GRAP 17, has often been the key contributor to these qualifications.

Effective municipal AM requires municipal officials to have a good understanding of the goals of AM for effective service delivery throughout an asset's life cycle. Officials must be aware that AM plans form an integral part of municipal planning and that it is not a stand-alone process. Effective AM requires that reporting must be in line with the applicable reporting standards and that such information must meet the requirements of various internal and external stakeholders (NT 2008:21). These guidelines indicate that municipalities will have to improve on the state of their affairs in terms of their infrastructure management starting by keeping an up-to-date asset register.

\section{Risk management}

According to $\mathrm{Nel}$ (2019):

Risk management is a management function, therefore management must identify risks, rate these risks in terms of exposure and then decide whether they are going to accept, avoid, or transfer the risk. If they want to avoid the risk, they would implement mitigating controls to address these risks. (p. 63)

The Public Sector Risk Management Framework (PSRMF) (NT 2010:15) defines risk 'as an unwanted outcome, actual or potential, to the Institution's service delivery and other performance objectives, caused by the presence of risk factor(s)'. The PSRMF states that some risk factor(s) also present benefits that the management of an organisation must be aware of and be prepared to exploit (NT 2010:15).

The non-maintenance of infrastructure is an example of internal risk and can result in the deterioration, or even abrupt stopping of critical service delivery standards. Other internal risks include fraud or misappropriation of the infrastructure, and the risk of inaccurate budgeting that can weaken the financial position of the municipality.

\section{The PSRMF (NT 2010) states that:}

Institutions must, in accordance with the prescripts, implement and maintain effective, efficient and transparent systems of risk management and internal control and that the institutions should through the risk management process achieve sustainable and reliable delivery of services, reducing waste, whilst achieving better outputs and outcomes through improved project and programme management. (p. 20)

In terms of King III, risk management is important and the council is responsible for the governance of risk and its disclosure, and the management is responsible for the risk management design, implementation and monitoring of the risk management plan (KPMG 2009:3). Further to this, the King IV report in terms of Principle 11 as it applies to local government states that the council should govern risk in such a way that it supports the organisation in setting and achieving its strategic objectives. This means that risk management sets the direction for how council approaches and addresses risk (Institute of Directors Southern Africa 2016:62). King IV thus requires a total overhaul of local government's current practices if it is to achieve effective risk management (Nel 2019:71).

\section{Research findings}

The following section consists of a triangulation of both qualitative and quantitative questions for the three municipal departments researched.

\section{Inputs to the environment}

Departments indicated that they are spending their repairs and maintenance (R\&M) budget in terms of the relevant vote; however, some of them face challenges and are forced to effect virements (transfers of budget amounts from other categories) in order to fulfil their maintenance roles.

\section{Population growth}

Only one out of three departments stated that it has a good idea of the movement of people by using the census figures 
and the annual socio-economic study indicators, but again they are hamstrung by funding to address the growth patterns, and it is also difficult to determine this growth during the periods of non-census. This non-availability of accurate current information makes planning for growth difficult, if not impossible.

\section{Value for money}

All departments stated that the council does get value for money; however, there is still much wastage, especially in terms of the supply chain management (SCM) processes, which do not take the needs of departments seriously in the timeous appointment of service contractors.

\section{Human skills and capacity}

Departments indicated that they have the necessary human skills and capacity in place for their normal operational requirements, and many of them are only now in the process of appointing staff for the management of infrastructure in terms of the new council-approved institutional review, which indicated that there are many shortfalls.

In terms of infrastructure management and the R\&M thereof, two departments indicated that they have succession plans in place, but the pool from which they can choose is not big enough to make it successful, or the intended successor normally finds other better opportunities before filling an identified post. The Systems Act also makes it difficult to retain staff, especially those who report directly to the municipal manager, because their appointment is for a fixed term of 5 years in terms of Section 57. What exacerbates the situation at the $\mathrm{COE}$, is that even the levels below the heads of departments (those of divisional heads) are also required to sign fixed term contracts of 5 years, thus they also create gaps at the expiration of their contracts and especially if their contracts are not renewed.

\section{Involvement of senior managers in infrastructure management and repairs and maintenance}

All departments indicated that some of their senior management's involvement ranges from limited, fair to high involvement as some of them delegate this function to a lower-level management that is not necessarily committed, or knowledgeable in order for them to meet their key performance areas (KPA's) in terms of R\&M spending. Senior management in many instances is only interested in whether spending has taken place, not so much on what it was spent and the quality of the work that has been performed. In terms of $\mathrm{R} \& \mathrm{M}$ and effective management of infrastructure, this does not help at all because senior management does not want to take responsibility for this very important line item of expenditure.

\section{Political support}

Two thirds of the departments indicated that they enjoy great political support in the management of infrastructure and R\&M. In cases where political oversight is lacking, such departments just deteriorate and the public experience the regression in the services they receive. Unfortunately, politicians are more concerned with the acquisition of new capital assets rather than looking after what the departments already have and are struggling to look after and maintain. Politicians must realise their important oversight roles that they play in the safeguarding and maintenance of infrastructure as they have the power to determine the allocation of funds, and even more, the impact infrastructure maintenance has on service delivery. Politicians must also resist the temptation of always wanting to build new libraries or clinics, whilst the city cannot even maintain after the current ones.

\section{Condition of infrastructure asset}

Only two thirds of the departments stated that they know the conditions of their assets, and they indicated that their asset register lacks credibility regarding certain assets. Especially in cases where assets are old and lack important information, then the date of proclamation of the township/area is used as the basis, which is often problematic. Some departments only have a fair understanding of the condition of their assets, making it impossible for them to timeously replace these assets or preparing to have the asset replaced before problems start to kick in.

\section{Asset register}

The asset register contains critical information such as the purchase price or the cost of building the asset, the date of acquisition, the R\&M already expended on it, depreciation written off, the remaining useful life (RUL) of the asset, possible impairment, etcetera. All departments know the details of how much they have on their respective asset registers; however, they do not always look at the details, especially not what has been spent on each asset in terms of $\mathrm{R} \& \mathrm{M}$ as the register is not being updated with such information. Apportionment of costs is and will be an administrative burden, but one department applies the straight line depreciation method and also uses other information that is superimposed on all their other assets in order to determine cost, replacement and depreciation.

\section{Capital infrastructure programme}

Only a third of the departments indicated that they have a capital infrastructure programme in place. One department is in the process of gathering information to put the programme in place; however, they have an investment programme in place until 2022, whilst the last department does not have anything in place. The question remains, how can the department have an investment programme if it does not have an infrastructure programme because one programme informs the other?

\section{Backlogs}

Departments stated that the eradication of backlogs is a constant challenge as people are flocking into the city in the hope of improving their lives and those of their children. 
Backlogs are to be defined and measured within specific timeframes as there is a constant movement of people and departments are chasing a moving target within their available budget. Only two departments indicated that they were able to reduce their backlogs. This remains a socioeconomic challenge for which the municipality takes responsibility, as people also see how successful the municipality is in terms of service delivery and this draws them to the city.

\section{Comprehensive municipal infrastructure plan}

All departments indicated that there is a Comprehensive Municipal Infrastructure Plan (CMIP) in place and only one of them complained that they had limited involvement in the compilation thereof. All departments indicated that there are sanctions in place for non-achievement of the objectives of the CMIP as the objectives form part of the performance targets of divisional heads and heads of departments. The achievement of the goals in the CMIP also requires a coordinated approach between the planning departments, the office dealing with Performance Management Systems (PMS) and the Enterprise Project Management Office (EPMO). Unfortunately, only two departments indicated that there is coordination between the CMIP, PMS and the EPMO. There is also an indication that the EPMO is non-existent, and they do not make an impact as envisaged with the establishment thereof. The EPMO's function is to coordinate the different projects of all departments and to speed up processes in the delivery of services, but over the years, it failed dismally in this regard. Only one third of the departments have a Maintenance Programme, a replacement programme and a decommissioning programme in place, whilst the others are in the process of having theirs approved.

\section{Processing of inputs}

All departments indicated they have measures or strategies in place to prevent continued repairs and that, in terms of normal operational requirements, continued repairs can never be prevented because of the nature of the service such as electricity, water, wastewater, roads and storm water. However, in the case of Roads \& Stormwater reactive maintenance is the order of the day: as a result of things like potholes, excessive storm water downpours etcetera, continuous repairs are done as and when required, just like in the case of follow-up repairs. Departments are to put in place systems that follow up on the quality of repairs undertaken by service providers.

All three departments indicated that they are able to determine the costs of downtimes or interruptions of their services because of non-maintenance of infrastructure; however, they all try their best to maintain their assets as best as they could.

Departments stated that they spent an average of approximately $8 \%$ of the annual R\&M budget on R\&M because of vandalism and theft; however, this figure can be even more if greater effort is made by the departments to determine the reasons for the R\&M. It is a concern when departments do not know what they are spending on: costs that could otherwise have been prevented had reasonable care been exercised in terms of control measures.

\section{Outputs to the environment}

Departments are required to reduce downtimes or interruptions through the application of effective R\&M measures.

In the case of electricity, water and wastewater, there are compliance benchmarks in place, and both departments stated that they are well within these benchmarks. However, the constant expansion of the electricity networks must be taken into account and where the number of faults remain the same; it actually means that the department is improving in reducing its downtimes or interruptions. Departments also indicated that the expansion of the networks does not necessarily correlate with an increase in the number of personnel to maintain these expanded networks. However, the challenge remains with regard to the traffic lights that are out after a storm and the economic impact thereof, are yet to be determined.

\section{Feedback from the environment}

In terms of the 2018-2019 annual financial statements of the $\mathrm{COE}$, the three technical departments combined form $59.41 \%$ of the direct actual expenditure of the municipality's total expenditure, of which the Energy department alone accounts for 34.4\% (COE 2020a:5). This means that these departments collectively play a major role in the delivery of services to the communities.

The Energy department accounts for $40.40 \%$, Roads \& Stormwater: $34.60 \%$ and Water \& Wastewater $20.00 \%$ of the city's R\&M total expenditure. The criticality of these departments is displayed in the $86.52 \%$ it represents of the total R\&M spending of the municipality.

For the average renewal of existing assets as a percentage of Capex, the average for the whole municipality is $58.97 \%$ which is good as the NT requirement is $40.00 \%$, whilst the three departments collectively average $80.70 \%$. This indicates that the municipality is consistently renewing its infrastructure base, but it can only be effective if there is an infrastructure management system in place. Such a system can measure whether the municipality is indeed renewing its existing infrastructure or is it just mere additions indicated as renewals and that these figures should be subject to annual internal audit processes.

The average for asset renewals as a percentage of PPE for the past 5 years is $3.62 \%$. This is far too low taking into account the individual spending of departments and that NT's generally accepted norm is $8.00 \%$. It further indicates that the city was only able to replace its PPE 3.6 times over the last 5 
years, something that is unacceptable and can lead to possible service interruptions.

In terms of the 2017-2018 annual report of the COE (2019:68), departments indicated their basic service and infrastructure backlogs (in terms of number of households) as water 1023 486, wastewater 989985 and energy as 559835 . Availability of funds and the constant movement of the target (because of influx of people, which is not necessarily bad, but which is difficult to control and to plan for), make it difficult for departments to make an impact in terms of addressing backlogs, this challenge is further exacerbated by aging infrastructure.

Unaccounted losses for the last 3 years in volume and in rand are:

- Electricity:

- 2016-2017: 1135074900 kW, R9 159611397 (COE 2019:note 52)

- 2017-2018: 1244154012 kW, R1 076496700 (COE 2020:note 51)

- 2018-2019: 1277342661 kW, R1 184000058 (COE 2020:note 51)

- Water:

- 2016-2017: 103475426 kL, R787 774009 (COE 2019:note 52)

- 2017-2018: 99415525 kL, R833 362612 (COE 2020:note 51)

- 2018-2019: 106370025 kL, R1 002005635 (COE 2020:note 51)

These losses include both technical and non-technical losses where the former relates to engineering and infrastructure issues such as heat dissipation in the case of electricity, and evaporation in the case of water. Technical losses on the other hand occur because of theft, poor payment, incorrect metering and other losses that are outside of the reticulation network.

The city is slowly succeeding in addressing its distribution losses and just for the 2018-2019 financial year, it lost R2.2b: money that could have been used to build at least 8800 houses for the poor if the cost of each house is estimated at R250 000.00.

In terms of Table 1, the municipality is doing well in terms of its average spending on R\&M, albeit with some challenges. The difference between direct expenditure, including bulk purchases and direct expenditure excluding bulk purchases is great because bulk purchases of electricity have increased drastically since 2009 because of supply challenges of Eskom, and their more than inflationary increases that were allowed by the National Electricity Regulator of South Africa (NERSA) in recent years. Both, Energy and Water \& Wastewater departments' average R\&M as a percentage of total metro expenditure is $25.3 \%$. This means that both departments are able to maintain their PPE relatively easily, despite their service delivery challenges of distribution losses. Another reason why these departments can have a high R\&M spend is that there is a special levy in place on their sale of electricity and water, which is ring-fenced for maintenance purposes.

Table 2 indicates that the city's average spending for the last 5 financial years based on the city, and even per department, is puny in that the NT general accepted norm is $8 \%$. The last time the Department of Energy met this requirement was during the 2013/2014 financial year (Patience 2015:157) because then there was just a total downward spiral for all of these important service delivery departments. The municipality cannot proceed with these low levels of spending on renewing its service delivery assets as its impact is already felt by the number of electricity black outs, the high number of potholes and non-availability of water for days on end.

Based on Table 3, the COE's average PPE grew only 9.47\% over 3 years; something that the city has to make amends for. However, in terms of service delivery infrastructure it has not grown that well. This means that other capital assets were acquired which do not contribute to sustainable service delivery. Unfortunately, the researcher did not have the financial information of cities such as eThekwini and Cape Town for the period under discussion; however, when comparing this ratio for the approved 2020-2021 Medium Term Revenue and Expenditure Framework (MTREF) against cities such as eThekwini and Cape Town, the COE lags behind in terms of capital acquisition. The COE's ratio was $9.5 \%$, whilst eThekwini and Cape Town showed 10.61\%

TABLE 1: Financial analysis and interpretation - Averages of repairs and maintenance over direct expenditure.

\begin{tabular}{lcccc}
\hline Averages for the past $\mathbf{5}$ years & $\begin{array}{c}\text { Metro } \\
(\mathbf{\%})\end{array}$ & $\begin{array}{c}\text { Energy } \\
\mathbf{( \% )}\end{array}$ & $\begin{array}{c}\text { Water and } \\
\text { wastewater (\%) }\end{array}$ & $\begin{array}{c}\text { Roads and } \\
\text { stormwater (\%) }\end{array}$ \\
\hline $\begin{array}{l}\text { R\&M/Direct expenditure } \\
\text { excluding bulk purchases }\end{array}$ & 10.21 & 18.57 & 14.94 & 0.00 \\
$\begin{array}{l}\text { R\&M/Direct expenditure } \\
\text { including bulk purchases }\end{array}$ & 6.21 & 4.99 & 6.27 & 29.94 \\
$\begin{array}{l}\text { Departmental expenditure/ } \\
\text { Total metro expenditure }\end{array}$ & 0.00 & 40.96 & 17.86 & 5.15 \\
$\begin{array}{l}\text { Departmental R\&M/Total } \\
\text { metro expenditure }\end{array}$ & 0.00 & 32.78 & 17.86 & 24.53 \\
\hline
\end{tabular}

$R \& M$, repairs and maintenance; excl., exclusive; incl., inclusive.

TABLE 2: Averages of renewals over total property, plant and equipment.

\begin{tabular}{lcccccc}
\hline $\begin{array}{l}\text { R\&M/Property, plant and } \\
\text { equipment (PPE) }\end{array}$ & \multicolumn{5}{c}{ Actual } & $\begin{array}{c}\text { 5 year } \\
\text { average }\end{array}$ \\
\cline { 2 - 7 } & $\mathbf{1 4 1 5}$ & $\mathbf{1 5 1 6}$ & $\mathbf{1 6 1 7}$ & $\mathbf{1 7 1 8}$ & $\mathbf{1 8 1 9}$ & \\
\hline Metro (\%) & 2.78 & 3.31 & 4.05 & 3.80 & 4.16 & 3.62 \\
Energy (\%) & 4.93 & 4.98 & 4.73 & 4.43 & 6.29 & 5.07 \\
Water and waste water (\%) & $\mathbf{2 . 1 2}$ & 3.86 & 5.20 & 4.89 & 4.03 & 4.02 \\
\hline Roads and stormwater (\%) & 0.75 & 1.24 & 4.07 & 3.82 & 4.46 & 2.87 \\
\hline
\end{tabular}

R\&M, repairs and maintenance.

TABLE 3: Averages of capital acquisition over total property, plant and equipment.

\begin{tabular}{lcccccc}
\hline $\begin{array}{l}\text { Total capital expenditure/ } \\
\text { property, plant and } \\
\text { equipment (PPE) }\end{array}$ & $\mathbf{1 4 1 5}$ & $\mathbf{1 5 1 6}$ & $\mathbf{1 6 1 7}$ & $\mathbf{1 7 1 8}$ & $\mathbf{1 8 1 9}$ & $\begin{array}{c}\text { 3 year } \\
\text { average }\end{array}$ \\
\cline { 2 - 6 } & 6.43 & 8.15 & 7.72 & 10.28 & 10.42 & 9.47 \\
\hline Metro (\%) & 4.60 & 4.01 & 4.78 & 5.23 & 5.10 & 5.04 \\
Energy (\%) & 5.41 & 7.74 & 3.27 & 5.82 & 7.42 & 5.51 \\
Water and waste water (\%) & 5.74 & \\
\hline Roads and stormwater (\%) & 3.73 & 4.83 & 2.23 & 6.14 & 5.23 & 4.53 \\
\hline
\end{tabular}


and 13\% respectively (City of Cape Town 2020:SA6; City of eThekwini 2020:SA6).

The COE with its ever-growing population cannot grow its asset base by not spending adequately on capital and not maintaining its current assets, and it will therefore have to make a concerted effort to improve these figures. Nonspending on critical infrastructure assets will catch up with the city's ability to render its constitutionally mandated services.

The NT's generally accepted norm is 40; this means that the city's total capital budget must at least cover $40 \%$ for renewals. The city must replace those assets that have reached the end of its useful lives with these renewals.

Table 4 indicates that Roads \& Stormwater, Water \& Wastewater and Energy departments have spent their entire capital budget on renewals during 2016-2017, 2017-2018 and 2018-2019 respectively. However, this can lead to a dispute because there had to be other forms of capital acquisitions as well. This clearly indicates the haphazard manner in which the NT schedule is followed; without giving a thought to accuracy. The 3-year average for the whole municipality is $58.97 \%$, which is a good indication that the municipality is renewing its infrastructure base, after comparing this figure with that of the City of Cape Town and eThekwini's: $21 \%$ and $31.5 \%$, respectively. Be that as it may, if the COE corrects these mistakes on its renewals, it will bring it in line with those of its comparable metros and it can only be effective if there is an infrastructure management system in place that can measure whether the city is really renewing its existing infrastructure, or is it just mere additions.

In order to see whether the $\mathrm{COE}$ is at least meeting international benchmarking standards in terms of its ability to replace its current infrastructure, the researcher checked what the city's PPE was at the end of the 2018-2019 financial year. Because the individual departmental PPE was not available, the researcher apportioned the departmental carrying value as supplied by the assets management

TABLE 4: Renewals over Capex.

\begin{tabular}{lcccccc}
\hline $\begin{array}{l}\text { Renewals/Capital } \\
\text { expenditure }\end{array}$ & \multicolumn{9}{c}{ Actual } & $\begin{array}{c}\text { 3 year } \\
\text { average }\end{array}$ \\
\cline { 2 - 7 } & $\mathbf{1 4 1 5}$ & $\mathbf{1 5 1 6}$ & $\mathbf{1 6 1 7}$ & $\mathbf{1 7 1 8}$ & $\mathbf{1 8 1 9}$ & \\
\hline Metro (\%) & 41 & 47.12 & 56 & 39 & 82 & 58.97 \\
Energy (\%) & 21 & 16.97 & 19 & 93 & 100 & 70.92 \\
Water and waste water (\%) & 8 & 26.83 & 34 & 100 & 81 & 71.62 \\
Roads and stormwater (\%) & 13 & 33.92 & 100 & 99 & 100 & 99.55 \\
\hline
\end{tabular}

division to that of the total of the three departments. The 2013 State of City Finances that was published by the South African Cities' Network (SACN 2013:94) used different South African metropolitan municipalities' current replacement costs (CRCs) to determine what the benchmarked R\&M should be, by using international norms. The actual R\&M was determined and compared with the benchmarked R\&M to find out whether the actual R\&M is adequate for the specific asset class.

In Table 5, the researcher used the same approach and formulae as proposed by the SACN, by using the CRC as at the end of 2018-2019 financial year. In the absence of the actual CRC the researcher used the carrying value and incrementing this by $40 \%$ because there are different asset classes, of which the useful lives differ from 5 to 80 years. Some of these asset classes have already reached the end of their useful lives and should have been replaced already, but because of the cost they cannot be replaced. The different asset classes, for example, electrical infrastructure would consist of high, mega and low voltage substations, switching stations, transmission conductors and networks. In terms of water and wastewater supply infrastructure, asset classes consist of boreholes, reservoirs, pumping stations, water treatment works, bulk mains, distribution points, reticulations, etcetera. The researcher compared the actual R\&M with international benchmarking requirements and found that the city is doing well in terms of both Energy and Water \& Wastewater departments, which were above the specified requirement by $18 \%$ and $5 \%$, respectively. However, the Roads \& Stormwater department is not spending adequately on R\&M and there is an under-spending of R180 million, which translates to $23 \%$. This under-spending is evident in the many potholes and the damages to the road surface in the city.

\section{Recommendations}

The following recommendations are discussed in terms of the elements of the system theory and the classification framework or model, namely inputs, processing, outcomes and feedback.

Inputs to the environment discuss how resources are to be employed in municipal service delivery from the planning phase right through to the reporting phase and how, legislative frameworks, regulations and policy directives, all impact this element of the systems theory, namely inputs to the environment. An important resource is that of human resources and how this resource is to be nurtured, developed and strengthened continually because without this resource,

TABLE 5: Comparison between the City of Ekurhuleni's repairs and maintenance and that of international benchmarking for the 2018-2019 financial year.

\begin{tabular}{|c|c|c|c|c|c|c|}
\hline Department & $\begin{array}{l}1819 \text { Actual } \\
\text { PPE at cost }\end{array}$ & $\begin{array}{c}\text { Apportionment of total } \\
\text { PPE (\%) }\end{array}$ & $\begin{array}{c}\text { Annual R\&M } 2.6 \\
\text { of CRC benchmarking (\%) }\end{array}$ & $\begin{array}{l}1819 \text { Actual } \\
\text { R\&M }\end{array}$ & $\begin{array}{l}\text { Difference in spending } \\
\text { between CRC and actual }\end{array}$ & $\begin{array}{c}\text { Variance of } \\
\text { R\&M/Actual R\&M (\%) }\end{array}$ \\
\hline Energy & 26995777712 & 33.87 & 701890221 & 858157792 & 156267571 & 18.21 \\
\hline Water and waste water & 15550269358 & 19.51 & 404307003 & 425313711 & 21006708 & 4.94 \\
\hline Roads and stormwater & 37158050101 & 46.62 & 966109303 & 785980565 & -180128738 & -22.92 \\
\hline Total & 79704097171 & 100 & 2072306526 & 2069452068 & -2854458 & 0 \\
\hline
\end{tabular}

R\&M, repairs and maintenance; CRC, current replacement cost; PPE, property, plant and equipment. 
the other resources such as finance cannot be effectively employed, and thus no services can be delivered.

Processing as the stage where the inputs are converted to outputs and outcomes is very important as this process is highly affected by the type of leadership provided within the municipality. Processing of inputs also concentrates on the human element and the role it plays in the service delivery chain in terms of motivation, employee engagement and guidance by senior management and political structures. All of this requires a strong Human Resource Management System as this is the arena where management, technology, systems and skills come together, which creates the shared view of service imperatives amongst officials, regardless of their positions and the jobs they are performing.

The quantitative results indicate what is expected from NT and international benchmarking requirements and how the COE must go about achieving these targets if it wants to be a municipality on which its communities rely. These results indicate which departments are really performing well and which departments have to upskill themselves in terms of service delivery. The one challenge that remains so difficult to overcome in the municipality is that of backlogs and the impact it has on the performance of departments. However, this must be seen against the backdrop of what other municipalities are doing which forces people to come to the COE for improved services.

Outcomes are discussed in terms of improved services and the risks that the municipality is facing. Outputs and outcomes are not synonyms in that outputs refer to the goods and services delivered by the municipality, whereas outcomes refer to the benefits that communities derive from such services, indicating what impact has been made by the municipality. This goes back to processing of the inputs whereas engagement of municipal officials in this phase impacts the outcomes of the municipality. Thus the interaction between officials and communities cannot be overemphasised as infrastructure management requires an integrated approach to the benefit of all stakeholders.

National and provincial governments determine outcomes for local government and the rationale of this is to strengthen the strategic focus around government's core priorities. These core priorities enable municipalities and other sector departments to carry out their constitutional and legislative mandates effectively, and to hold them accountable for their performances. Therefore, the government's approach to this is that service delivery protests are but one indication of the local government's critical role in the development and growth of people. Departments at both national and provincial levels must ensure that they know and understand their roles and responsibilities in terms of service delivery, especially that of basic municipal services.

Feedback from the environment as a process of the systems theory takes place when information and knowledge is shared amongst all stakeholders to assess whether the overall results are achieved in terms of the set programmes.

Feedback is only possible when there is a good PMS in place and it should be used in conjunction with the goals that were set. Continuous feedback is to be encouraged from communities in order for the municipality to know whether they are making a difference, and these feedback processes are to be at the organisational, strategic and programme level and not at the project-level. Feedback requires management buy-in from the highest level in order for it to be effective, and it requires competent staff to operate these centres and great investment from the municipality. Benchmarking as a process forms part of feedback, and the COE was benchmarked against other metropolitan municipalities to see how it is faring in terms of infrastructure management against them.

Population growth is also part of the feedback element as it indicates to the municipality that people want to live here because of services that are rendered, even though the municipality may find it difficult to render such services because of continuing backlogs. The city's population growth is in line with the national average, the only thing these people want is to improve their lot, and this drives them to the cities. Urbanisation is a powerful element and it is an irreversible force worldwide. However, in order to reduce poverty and provide adequate housing, infrastructure, education, health, safety and basic services, a strong urban economy is essential. This is where infrastructure services can contribute to economic growth and development and the promotion of social equity. The development of infrastructure services leads to growth; growth again contributes to infrastructure development that again leads to human capital development, so these cycles are constantly feeding each other.

Systems theory and its benefits can assist public managers to see problems within the right context to broaden their perspectives regarding the challenges at hand. The systems theory can help governments to consider how their decisions will affect other components of the system and the environment in which they operate. By looking through the systems theory lens, they can get a holistic approach that is both complete and functional.

Systems thinking can help public governance officials to: avoid undue simplifications, and it can provide useful tools for dealing practically with differences. Systems thinking can also contribute by looking beneath the surface of observable phenomena to bring about new ways of understanding, by identifying those underlying patterns and causes. Public officials by using systems thinking can provide simple insights into the functioning of complex systems and bring about new insights and improving joint understanding of issues across a range of stakeholders. 


\section{Conclusion}

The results for the city will be dire if it does not implement these recommendations as outlined in this article. The implementation of these recommendations requires political will that can lead to increased revenue for the city that in turn, will lead to infrastructure expansion, resulting in more people and businesses moving here. Many other externalities will follow, such as increased building of education facilities, greater educated workforce for both public and private entities, greater revenue for the municipality and a reduction in indigent numbers. The improvement of governance within the city will lead to achieving clean audits, but not only that, communities will have greater confidence and trust in their city's ability to act according to legislation and other legal prescripts.

\section{Acknowledgements Competing interests}

The authors declare that they have no financial or personal relationships that may have inappropriately influenced them in writing this article.

\section{Authors' contributions}

J.J.P. was the main author, and D.N. the co-author and supervisor on this article. Both authors contributed to the design and implementation of the research, to the analysis of the results and to the writing of the manuscript.

\section{Ethical considerations}

This article followed all ethical standards for research without direct contact with human or animal subjects.

\section{Funding information}

This research received no specific grant from any funding agency in the public, commercial, or not-for-profit sectors.

\section{Data availability}

The data that support the findings of this study are available on request from the corresponding author J.J.P., upon reasonable request.

\section{Disclaimer}

The views and opinions expressed in this article are those of the authors and do not necessarily reflect the official policy of position of any affiliated agency of the authors.

\section{References}

Auditor General, 2012, Auditor General Report for 2011/2012 financial year, Auditor General, Pretoria.
Babbie, E.R., 2010, The practice of social research, 12th edn., Wadsworth, Belmont, CA.

Boshoff, L., 2009, Municipal infrastructure asset care in South Africa: A reality check, viewed 26 May 2014, from http://www.iatconsulting.co.za/published/Municipal\% 20Asset\%20Care\%20in\%20South\%20Africa_A\%20Reality\%20Check.pdf.

City of Cape Town, 2020, A1 schedule 20/21 medium term revenue and expenditure framework, City of Cape Town, Cape Town.

City of Ekurhuleni (COE), 2015, Aerotropolis Ekurhuleni - Gauteng Global City Region, Ekurhuleni Metropolitan Municipality, Germiston.

City of Ekurhuleni (COE), 2019, Annual financial statements, City of Ekurhuleni, Germiston.

City of Ekurhuleni (COE), 2020a, Annual financial statements, City of Ekurhuleni, Germiston.

City of Ekurhuleni (COE), 2020b, A1 schedule 2020/2021 medium term revenue and expenditure framework, Ekurhuleni Metropolitan Municipality, Germiston.

City of eThekwini, 2020, A1 schedule 2020/2021 medium term revenue and expenditure framework, City of eThekwini, Durban.

Currency Converter, 2021, Currency Converter, viewed 08 January 2021, from https:// www.xe.com/currencyconverter/convert/?Amount $=60000000000 \&$ From $=$ ZAR\&To=USD.

Department of Cooperative Governance and Traditional Affairs (CoGTA), 2009, Overview report on the State of Local Government in South Africa, Government Printers, Pretoria.

Gildenhuys, J.S.H. \& Knipe, A., 2000, The organization of government: An introduction, Van Schaik, Pretoria.

Institute of Directors Southern Africa, 2016, King IV: Report on Corporate Governance for South Africa, Institute of Directors South Africa, Johannesburg.

Jabareen, Y., 2009, 'Building a conceptual framework: Philosophy, definitions, and procedure', International Journal of Qualitative Methods, International Institute for Qualitative Methodology (IIQM) 8(4), 49-62. https://doi.org/10.1177/ 160940690900800406

KPMG, 2009, Corporate Governance and King III, KPMG, Johannesburg.

Marshall, M.N., 1996, 'Sampling for qualitative research', Family Practice Journal 13(6), 522-525. https://doi.org/10.1093/fampra/13.6.522

National Treasury (NT), 2008, Local Government Capital AM guidelines, Government Printers, Pretoria.

National Treasury (NT), 2010, Public sector risk management framework, Government Printers, Pretoria.

Nel, D., 2019, 'Risk management in the South African local government and its impact on service delivery', International Journal of Management Practice 12(1), 60-80. https://doi.org/10.1504/IJMP.2019.10017278

Neuman, W.L., 1997, Social research methods: Qualitative \& quantitative approaches, 3rd edn., Allyn \& Bacon, Needham Heights, MA.

Patience, J.J., 2015, 'Infrastructure management challenges in Ekurhuleni Metropolitan Municipality', Unpublished Master's dissertation, University of Johannesburg, Johannesburg.

Republic of South Africa, 1996, Constitution of the Republic of South Africa, Act no. 108 of 1996, Government Printers, Pretoria.

Republic of South Africa, 1998, Local Government: Municipal Structures act, Act no. 117 of 1998, Government Printers, Pretoria.

Republic of South Africa, 2000, Local Government: Municipal Systems Act, Act no. 32 of 2000, Government Printers, Pretoria.

Republic of South Africa, 2001, Draft Municipal performance management regulations of 2001, Government Printers, Pretoria.

Republic of South Africa, 2003, Local Government: Municipal Finance Management Act, Act no. 56 of 2003, Government Printers, Pretoria.

Republic of South Africa, 2013, Spatial Planning and Land Use Management Act, Act 16 of 2013, Government Printers, Pretoria.

Schermbrucker, 2020, We won't fix development until we fix our municipalities, viewed 28 September 2020, from https://www.dailymaverick.co.za/article/202007-30-we-wont-fix-development-until-wefix-our-municipalities/\#gsc.tab=0.

Sosibo, K., 2014, 'SA's unspent cash blocks water flow', Mail \& Guardian, March 7-13, p. 10.

South African Cities' Network (SACN), 2013, 2013 State of city finances - Towards sustainable municipal finances, SACN, Braamfontein.

South African Institute of Civil Engineers (SAICE), 2011, SAICE infrastructure report card for South Africa, SAICE, Midrand.

Statistics South Africa, 2012, 2011 Census results, viewed 04 December 2020, from http://www.statssa.gov.za/?page_id =1021\&id=ekurhuleni-municipality

Van der Waldt, G. \& Auriacombe, C.J., 2015, UJ internal handbook-course PMG 2A11: Section A: Service delivery: Stakeholders, mechanisms and approaches, University of Johannesburg, Johannesburg. 